\title{
A prática de Iniciação à Pesquisa em uma turma de alfabetização
}

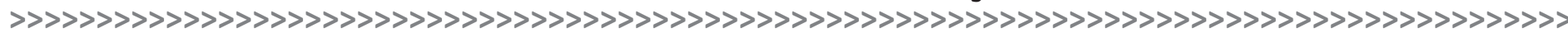

Maria Elisa de Araújo Grossi* Patrícia Barros Soares Batista**

\section{Resumo:}

Este artigo tem como objetivo apresentar o trabalho desenvolvido em uma turma de 1.은 ano do 1. Ciclo no Centro Pedagógico da UFMG, em 2016, nas aulas de Iniciação à Pesquisa, disciplina que tem como proposta assegurar que as crianças pesquisem temas de interesse, por meio de grupos de estudo formados de acordo com os temas escolhidos. O foco é fazer com que os educandos vivenciem e aprendam várias etapas e habilidades relacionadas à pesquisa científica. A metodologia de trabalho utilizada foi o ensino investigativo, uma ferramenta didática organizada a partir dos seguintes elementos: pergunta, busca e interpretação de informações, escrita, socialização dos resultados (por meio das linguagens oral e escrita). Apoiamo-nos na concepção de ensino experimental e investigativo, buscando romper com um tipo de educação formal focada na repetição de informações. Visamos à familiarização do estudante com a pesquisa, orientando-o para a investigação de fenômenos e temas que evidenciam a utilidade do conhecimento científico para o bem-estar social e para a formação de cidadãos críticos. É possível afirmar que o trabalho de Iniciação à Pesquisa, desenvolvido com as crianças pequenas, possibilitou uma nova forma de organização dos tempos e espaços escolares, contribuindo para a ampliação do currículo.

\section{Palavras-chave:}

Infância. Iniciação à Pesquisa. Produção de conhecimento. Letramentos.

\begin{abstract}
:
The purpose of this article is to present the work developed at the Introduction to Research course with first year students from elementary school at Centro Pedagógico da UFMG, in 2016. This course aims at allowing children to conduct group research on topics of their own choice. The focus is to stimulate the children to learn and practice the several skills and procedures often used in scientific research. The utilized work methodology was the investigative teaching, a didactic tool characterized by the following elements: question making, searching for and interpreting information and written and verbal sharing of results. We based our work on the conception of investigative and experimental teaching trying to break with the formal education strategy focused on information repetition. We intended to bring the students closer to scientific research by mentoring them on phenomena investigation and supporting them on the exploration of topics that shows the usefulness of the scientific thought for enhancing social welfare and shaping conscientious citizens. It is noteworthy that the work developed with little children at the Introduction to Research course has created a new framework for teaching, contributing to broaden the students' curriculum.
\end{abstract}

\section{Keywords:}

Childhood. Introduction to Research. Knowledge production. Literacy.

\footnotetext{
* > Doutora em Educação. Professora alfabetizadora do Centro Pedagógico da Escola de Educação Básica e Profissional da UFMG. Ministrou a disciplina "Iniciação à Pesquisa”, em parceria com a professora Patrícia Barros Soares Batista, coautora do artigo enviado. E-mail: meagrossi@ yahoo.com.br

** > Mestre em Educação. Professora alfabetizadora do Centro Pedagógico da Escola de Educação Básica e Profissional da UFMG. Ministrou a disciplina "Iniciação à Pesquisa”, em parceria com a professora Maria Elisa de Araújo Grossi. E-mail: patriciab.ufmg@gmail.com
} 
Introdução

Sem pesquisa não há ciência, muito menos tecnologia. Marcos Bagno

Tradicionalmente, o ensino organiza-se em torno de um professor, posicionado à frente da turma, que transmite o conhecimento a um aluno que está pronto para absorver e repetir os ensinamentos do mestre. Após o ensino, o aprendiz é avaliado e necessita repetir os conteúdos que lhe foram ensinados. Esse modelo tem vigorado nas escolas do Brasil há muitos anos e percebe-se certa dificuldade dos sistemas educacionais para superá-lo. Entretanto, os desafios em relação ao ensino contemporâneo são muitos e o desenvolvimento de pesquisas em educação tem mostrado que esse modelo, nomeado por Freire (1974) como Educação Bancária, desconsidera o papel do aluno como sujeito de seu processo de aprendizagem e produtor de conhecimento.

Assim, no século XX, foi surgindo, como reação ao modelo tradicional de ensino, uma série de tentativas de atribuir ao aluno um papel mais ativo, mais independente e responsável por seu aprendizado (ALBERGARIA, 2010). Uma dessas tentativas foi o surgimento de uma concepção de educação que defendia um ensino mais dinâmico, no qual os aprendizes fossem incentivados a aprender por meio da resolução de problemas a partir de perguntas iniciais. A concepção de ensino experimental e investigativo surge dentro dessa perspectiva, buscando romper com a educação formal focada na repetição de informações, habilidade comumente utilizada em nossas escolas. Essa concepção visa à familiarização do estudante com a pesquisa, orientando-o para a investigação de fenômenos e temas que evidenciam a utilidade do conhecimento científico para o bem estar social e para a formação de cidadãos, oferecendo, assim, possibilidades de ampliação do currículo escolar que qualificam o ensino.

O currículo é aqui compreendido como um espaço de ensino por excelência, ambiente privilegiado para experimentações, vivências e práticas. Para Lima (2007, p. 19), "a escola é um espaço de ampliação da experiência humana, devendo, para tanto, não se limitar às experiências cotidianas da criança e trazendo, necessariamente, conhecimentos novos, metodologias e as áreas de conhecimento contemporâneas." Nessa perspectiva, o currículo torna-se um instrumento de formação humana, pois introduz sempre novos conhecimentos, ampliando aqueles relacionados às vivências do aluno e às realidades regionais. Ainda segundo a autora, o conhecimento é um bem comum, devendo, portanto, ser socializado a todos os seres humanos. Para tanto, o currículo é o instrumento por excelência dessa socialização.

O ser humano realiza aprendizagens variadas durante a sua vida. Segundo Lima (2002, p. 5), a aprendizagem provoca modificações estruturais importantes no funcionamento psíquico, possibilitando o desenvolvimento das funções psicológicas superiores: atenção voluntária, percepção, memória e pensamento (Vigotski, 2002). Essas funções são essenciais no processo de desenvolvimento do ser humano e podem ser desenvolvidas na escola.

O ensino por investigação é um método que tem como finalidade a aprendizagem por meio de situações-problema que desenvolvam habilidades cognitivas relevantes a todas as áreas de conhecimento, focando o ensino no aluno que assume um papel de sujeito e produtor de conhecimento. "Na atividade de investigação, o aluno deve projetar e identificar algo interessante a ser resolvido [...]” (OLIVEIRA, 2010, p. 150). O ensino por investigação favorece o desenvolvimento das funções psicológicas superiores, essenciais no processo de aprendizagem, uma vez que estimula a atenção, a percepção, a memória e a organização do pensamento. 
A escola é uma grande possibilidade para o desenvolvimento do ser humano, por isso é imprescindível planejar ações pedagógicas que permitam a troca e a produção de conhecimento pelos educandos. Lima (2009, p. 5) destaca que, para que o ser humano se aproprie dos conhecimentos escolares, é necessário, em qualquer idade, que ele realize atividades específicas destinadas à formação de novas memórias. Essas atividades precisam ser ensinadas pelos professores, uma vez que são produtos do desenvolvimento cultural da humanidade. Desse modo, o conhecimento se torna não apenas uma aquisição individual, mas uma das possibilidades de desenvolvimento integral da pessoa, que terá reflexos na vida em sociedade, uma vez que o educando aprende, desde criança, a produzir e a compartilhar saberes com o outro.

Consideramos que o desenvolvimento de grupos de pesquisa é uma maneira de proporcionar atividades específicas de aprendizagem. Essa estratégia pedagógica instaura processos dialógicos na sala de aula, nos quais há um compartilhamento de conhecimentos e produção conjunta de novos saberes, proporcionando a apropriação de novas memórias.

\footnotetext{
A aprendizagem se efetua pela criação de novas memórias e pela ampliação e transformação de redes neuronais que "guardam" conteúdos já trabalhados anteriormente. Nesse processo, entram tanto as informações organizadas em conteúdos de memória (aprendizagem de conceitos), como a apropriação de metodologias que são os recursos para formação e/ou ampliação de memórias (LIMA, 2009, p. 10).
}

Trabalhar com grupos de pesquisa favorece a produção conjunta de novos saberes. Essa estratégia pedagógica é uma forma de iniciar os aprendizes na prática de pesquisa e busca de informações a respeito de algum tema de interesse deles ou proposto pelo professor. Quando trabalha em grupo, o aluno tem a oportunidade de aprender com o colega e de ampliar o seu próprio conhecimento. É possível afirmar que o trabalho com grupos de pesquisa é uma maneira de ensinar a aprender.

A partir do acesso a fontes de conhecimento, os educandos são orientados a como proceder para buscarem as informações que desejam, para selecionarem o que é mais importante e elaborarem algumas sínteses, sistematizando os conteúdos relevantes. Nesse processo, o professor assume um papel fundamental de orientador da aprendizagem, participando de todo o processo de pesquisa e de produção de conhecimento.

Ensinar a aprender, então, é não apenas mostrar os caminhos, mas também orientar o aluno para que desenvolva um olhar crítico [...] que lhe permita reconhecer as trilhas que conduzem às verdadeiras fontes de informação e conhecimento (BAGNO, 2007, p. 15, grifo do autor).

Segundo Bagno (2007, p. 17), a palavra pesquisa origina-se do espanhol, que, por sua vez, herdou-a do latim, perquiro, que significava "procurar, buscar com cuidado, informar-se". Os significados do verbo em latim revelam a ideia de pesquisa como uma busca feita com cuidado. Essa busca precisa ser ensinada ao aluno desde os anos iniciais do Ensino Fundamental. Bagno (2007, p. 18, grifo do autor) ainda destaca que a pesquisa é o fundamento de toda e qualquer ciência.

Ao propormos o trabalho com os grupos de pesquisa numa turma de primeiro ano em processo de alfabetização, nos interessava orientar as crianças para que iniciassem esse aprendizado de busca cuidadosa e reflexiva para obterem um conhecimento específico e estruturado sobre o assunto que haviam escolhido para aprofundamento. Assim, as atividades de leitura e de escrita teriam maior sentido para esses educandos, visto que procurariam responder a questões específicas de pesquisa. Concordando com Bagno (2007, p. 18) que a pesquisa é o fundamento de toda e qualquer ciência, julgávamos de suma 
importância iniciar essa prática desde os anos iniciais, por isso a implementação dessa proposta pedagógica no $1 .^{\circ}$ Ciclo de Formação Humana do Centro Pedagógico da Escola de Educação Básica e Profissional da Universidade Federal de Minas Gerais ${ }^{1}$.

A investigação, a descoberta (da nova informação, do fato ou fenômeno) e o confronto com o corpo de conhecimento já constituído, permitem o desenvolvimento do conceito. Assim, a atividade de pesquisa é essencial ao processo de apropriação do conhecimento formal, pois somente por meio do domínio do "fazer" (a metodologia de pesquisa) o aluno terá autonomia diante de seu próprio processo de aprendizagem e desenvolvimento (LIMA, 2009, p. 6).

Numa sala de aula em processo de alfabetização, o papel do professor adquire um caráter cada dia mais fundamental no que se refere ao estímulo à leitura e à pesquisa. A ação docente é contínua e intensa nesse espaço, e suas intervenções são essenciais para a efetiva aprendizagem dos alfabetizandos em processo de apropriação da língua escrita.

Quanto menos se lê, menor é a capacidade de compreensão do texto escrito; quanto menos se escreve, menos facilidade se tem para encontrar as construções sintáticas e as palavras exatas para comunicar o que temos a dizer (LIMA, 2009, p. 9).

$1>0$ Centro Pedagógico é uma escola de aplicação responsável pelo ensino fundamental de nove anos (desde 2006) Organizado em Ciclos de Formação Humana (desde 1995), adota o sorteio público para ingresso dos alunos, por considerá-lo a forma mais democrática, evitando mecanismos de seletividade que favoreçam quaisquer grupos sociais. Assim, atualmente, o Centro Pedagógico ministra o Ensino Fundamental, tendo-o como base investigativa para a produção de conhecimento em ensino, pesquisa e extensão. Seu objetivo maior é constituir-se como campo de experimentação e de pesquisa na Educação Básica e na formação de professores e de profissionais que têm o ambiente escolar como campo de atuação. São objetivos dessa Escola: ministrar o Ensino Fundamental, tendo-o como base investigativa para a produção de conhecimento, de ensino e de pesquisa; constituir-se como campo de reflexão e de investigação sobre a prática pedagógica; constituir-se como espaço de novas experimentações pedagógicas, que subsidiem avanços e reflexões sobre a prática educativa; servir de Campo de Estágio para alunos da Licenciatura e da Graduação.
A autora ressalta a importância da leitura e da realização de atividades de produção escrita de forma sistemática e contínua numa turma em processo de alfabetização. $\mathrm{O}$ trabalho de iniciação à pesquisa, por sua vez, exige a organização de tempos e espaços para se garantir o desenvolvimento de habilidades de leitura e de produção de textos escritos. Percebe-se, assim, a sintonia do trabalho de alfabetização com a proposta de Iniciação à Pesquisa, visto que as crianças, nas duas iniciativas, são convidadas a ler e a escrever continuamente.

Em todo esse processo, é de fundamental importância considerar que crianças pequenas compreendem e vivem a realidade natural e social de modo diferente dos adultos. Fora ou dentro da escola, as crianças emprestam magia, vontade e vida aos objetos e às coisas da natureza ao elaborar suas explicações sobre o mundo. Suas hipóteses sobre os fenômenos, muitas vezes, manifestam essas características de seu processo natural de desenvolvimento. Contudo, em torno de oito anos, as crianças passam a exibir um modo menos subjetivo e mais racional de explicar os acontecimentos e as coisas do mundo, em virtude das experiências que vai acumulando e das aprendizagens que realizam. Aos poucos, são capazes de distinguir os objetos das próprias ações e organizar etapas de acontecimentos em intervalos de tempo. Dessa forma, nos primeiros anos do Ensino Fundamental, são inúmeras as possibilidades de trabalho com os diferentes conteúdos do currículo, particularmente da área de Ciências Naturais, disciplina muito apreciada pelos pequenos aprendizes. Assim, considerando as características do desenvolvimento infantil, é importante que o trabalho pedagógico aconteça, primeiramente, de um modo mais lúdico e interativo para, paulatinamente, ir aprofundando de maneira mais sistematizada nas diferentes formas de registros.

Em geral, as crianças são bastante curiosas e se interessam muito por temas relacionados ao ambiente, por isso, desde o início do processo de escolarização e alfabetização, os temas de natureza científica, por sua presença variada no mundo e, por conseguinte, no próprio currículo, permitem o planejamento de relevantes propostas pedagógicas, dentre as quais destacamos o trabalho de iniciação à pesquisa. Ele garante diferentes formas de expressão dos aprendizes durante o processo, de modo que o aprendizado, interdisciplinar, possibilita às crianças aprender a intervir conscientemente no mundo. A seguir, explicitaremos a metodologia do trabalho pedagógico que foi realizado com as crianças. 


\section{Metodologia da proposta pedagógica de Iniciação à Pesquisa}

O trabalho em questão foi desenvolvido em uma turma de $1 .^{\circ}$ ano do $1 .^{\circ}$ Ciclo de Formação Humana, no Centro Pedagógico da UFMG, durante as aulas de Iniciação à Pesquisa, no ano de 2016. A partir dessa disciplina, pretendeu-se possibilitar aos educandos o protagonismo no processo de produção de conhecimento por meio da metodologia de ensino investigativo. A proposta assegura que as crianças pesquisem assuntos de seu interesse, por meio da organização de grupos de estudo de acordo com os temas escolhidos pelos aprendizes sob a orientação do professor.

O foco da disciplina de Iniciação à Pesquisa é fazer com que as crianças aprendam várias habilidades e etapas relacionadas ao universo da pesquisa científica tais como: definição do tema; elaboração de perguntas sobre o assunto escolhido, seleção de fontes seguras de pesquisa (livros, revistas, vídeos, jornais, enciclopédias, sites, etc.); leitura, interpretação e registro de informações; análise e sistematização dos dados e apresentação (oral e escrita) dos resultados. A busca, a seleção, a comparação e o pensamento crítico acerca das informações levantadas ajudam os aprendizes a construírem o conhecimento. É possível perceber que esse processo é complexo, mas pode ser aprendido desde os anos iniciais como demonstrou a experiência realizada.

O trabalho desenvolvido articula conhecimentos dos campos de Ciências Naturais e Ciências Humanas e ocorre uma vez por semana com a carga horária de $2 \mathrm{~h} / \mathrm{aula}$. A metodologia de trabalho utilizada foi o ensino investigativo, uma ferramenta didática organizada a partir dos seguintes elementos: pergunta inicial, busca e interpretação de informações, produção escrita de sínteses e socialização dos resultados (por meio da exposição da produção escrita e comunicação oral). O trabalho na turma se deu da seguinte forma: inicialmente, cada criança foi estimulada a pensar em um tema que gostaria de pesquisar. Para cada tema escolhido, ela foi convidada a delimitar uma pergunta inicial sobre o assunto, questão essa que estimularia a busca de informações e produção de conhecimento.

A pergunta de cada criança foi registrada, ${ }^{2}$ e, a partir daí, iniciou-se o percurso investigativo. Após o registro escrito das perguntas iniciais, geradoras do trabalho de pesquisa, foram formados grupos de estudo, integrando as perguntas de temas afins. Durante as aulas, as crianças trabalharam nesses grupos, orientadas pelas duas professoras-referência da turma, que trabalhavam de forma compartilhada dividindo todas as etapas referentes ao planejamento, execução, apresentação da produção e avaliação.

Pretendeu-se proporcionar profícuos momentos de busca de informações e de aprofundamento de conhecimentos sobre os temas escolhidos pelos discentes, que se dividiram em seis grupos: Dinossauros; Natureza 1; Natureza 2; Corpo e Tempo; Filmes e Desenhos; Jogos, Brinquedos e Brincadeiras. Para que o trabalho pudesse se desenvolver, os pequenos pesquisadores tiveram acesso a diferentes fontes de pesquisa como livros, revistas, folhetos, internet, vídeos, dentre outros. Tendo como referência a idade das crianças, seis anos em média, o trabalho visou contemplar as suas potencialidades, bem como aperfeiçoar o processo de apropriação da língua escrita, focalizando uma abordagem interdisciplinar de produção de conhecimento.

Por meio da prática de ensino investigativo, a construção do conhecimento se dá de modo interdisciplinar. A interdisciplinaridade é, portanto, entendida aqui como abordagem teórico-metodológica em que a ênfase incide sobre o trabalho de integração das diferentes áreas do conhecimento, um real trabalho de cooperação e troca, aberto ao diálogo e ao planejamento (BRASIL, 2013, p. 27). Segundo as Diretrizes Curriculares Nacionais para a Educação Básica, essa orientação deve ser enriquecida por meio de proposta temática trabalhada transversalmente ou em redes de conhecimento e de aprendizagem e
2 > Algumas perguntas elaboradas pelas crianças: Como o sangue é produzido? Como as plantas morrem? Como o tempo funciona? Como o broto vira flor? Como os dinossauros morreram? Como se pega Dengue, Zica e Chikungunya? Por que as árvores morrem? Como os homens da caverna conseguiam comida? 
se expressa por meio de uma atitude que pressupõe planejamento sistemático e integrado e disposição para o diálogo.

Após a formação dos seis grupos e delimitação dos temas, passamos a buscar diferentes fontes que serviriam como suporte para a pesquisa a ser realizada. A partir da divisão dos grupos e disponibilização das fontes, durante as aulas foram criados momentos de estudo, discussão e produção de conhecimento sobre os assuntos. Buscouse possibilitar o acesso a fontes variadas de pesquisa sobre cada tema. Durante as aulas, os alunos eram orientados a como buscar e registrar as informações para aprender. $\mathrm{O}$ trabalho era intenso e exigiu muito das professoras-referência, que contaram com a ajuda de monitores da graduação. ${ }^{3}$

Os Parâmetros Curriculares Nacionais de Ciências Naturais (PCN) já assinalavam que no $1 .{ }^{\circ}$ Ciclo a escola deve possibilitar o desenvolvimento de competências que permitam ao aluno "compreender o mundo e atuar como indivíduo e como cidadão, utilizando conhecimentos relacionados à natureza científica e tecnológica para tal" (BRASIL, 1997, p. 45). A Base Nacional Comum Curricular (BNCC), publicada em 2017, apresenta como um dos objetivos do ensino de Ciências: "Exercitar a curiosidade intelectual e recorrer à abordagem própria das ciências, incluindo a investigação, a reflexão, a análise crítica, a imaginação e a criatividade para investigar causas, elaborar e testar hipóteses [...]”. No trabalho de iniciação à pesquisa, os educandos produzem conhecimentos relacionados a temas de seu interesse, são incentivados a exercitar a curiosidade, a criatividade bem como a elaborar hipóteses sobre temas de interesse. Na proposta, além de buscar atingir esses objetivos, a dinâmica da aula visa abarcar objetivos traçados para o $10^{\circ}$ Ciclo de Formação Humana no que tange à sistematização da alfabetização.

Assim, há também a preocupação de que as crianças possam apropriar-se do sistema de escrita ao mesmo tempo em que ampliam as habilidades relacionadas ao letramento científico. O Instituto Nacional de Estudos e Pesquisas Educacionais Anísio Teixeira (INEP) entende como letramento científico "a capacidade de empregar o conhecimento científico para identificar questões, adquirir novos conhecimentos, explicar fenômenos científicos e tirar conclusões baseadas em evidências sobre questões científicas.” A perspectiva investigativa, que contribui com o processo de construção do letramento científico do sujeito, pode estimular o estudante a elaborar e construir "seus primeiros significados sobre o mundo, ampliando seus conhecimentos, sua cultura, sua possibilidade de compreender e participar efetivamente na sociedade em que se encontra inserido" (LORENZETTI; DELIZOICOV, 2001). Assim, a escola evidencia um de seus principais papéis: colaborar para que o educando tenha melhor compreensão do mundo e suas transformações, desenvolvendo habilidades e competências para que possa usar conscientemente o conhecimento científico.

O processo vivenciado em sala de aula durante as aulas de Iniciação à Pesquisa mostrou-se extremamente rico e dinâmico. Posteriormente à formulação de questões individuais que incentivaram a pesquisa, conceitos científicos básicos foram trabalhados com as crianças ao longo de todo o processo, de acordo com as dúvidas que surgiam. Observou-se a necessidade de preparação dos educandos para o trabalho em grupo, que proporciona a ação cooperativa entre os integrantes e a construção coletiva do conhecimento.

O trabalho realizado em sala de aula buscou articular interdisciplinarmente as diferentes áreas de conhecimento do currículo do $1 .^{\circ}$ Ciclo, focando especialmente as disciplinas de Língua Portuguesa, Ciências, Geografia, História e Artes. Por se tratar de crianças em processo inicial de alfabetização, os aprendizes tiveram a oportunidade de ter contato com informações fundamentais a respeito dos diferentes temas que escolheram

$3>0$ Centro Pedagógico possui um projeto de formação de professores conhecido como Imersão Docente. Esse projeto seleciona alunos de diferentes cursos da Graduação da UFMG para atuarem nas turmas. por meio da mediação contínua das professoras. Tomando como base os conhecimentos prévios de cada discente sobre os diferentes assuntos a serem pesquisados, buscamos, então, ampliar esses saberes por meio do levantamento de informações, comparação e produção de novos conhecimentos sobre os temas. 
Além da ampliação dos conhecimentos prévios das crianças, a atividade com os grupos de pesquisa visou, também, estimular a criatividade e inventividade dos estudantes. Além da produção de textos sobre os assuntos escolhidos, os aprendizes foram estimulados a ilustrar os registros escritos que produziam, utilizando, assim, outras linguagens como forma de representação de suas ideias.

A criatividade das crianças foi permanentemente estimulada e o trabalho gerou a produção de um livro de registro para cada grupo de pesquisa. Nesse livro, cada criança registrou suas sínteses sobre os temas pesquisados e ilustrou os textos produzidos. Além da construção do livro, os alunos produziram cartazes sobre os temas estudados em cada grupo.

Entendendo que a avaliação deve sempre se preocupar com a aprendizagem dos alunos, tomamos por base a avaliação formativa, isto é, uma avaliação "que ajuda o aluno a aprender e o professor a ensinar" (PERRENOUD, 1999, p. 173). Buscamos observar todo o processo de aprendizagem do aluno: conceitos iniciais, ideias e atitudes apresentadas durante o processo de investigação. Um momento crucial no conjunto dessa proposta foi a apresentação oral do que foi aprendido e produzido pelo grupo para toda a turma. As crianças foram estimuladas a expor aos colegas o que aprenderam na investigação realizada nas aulas de Iniciação à Pesquisa, particularmente a pensarem sobre a pergunta inicial que possuíam e as aprendizagens realizadas após todo o processo.

\section{Considerações finais}

A sala de aula pode ser um profícuo espaço de produção de conhecimento. A criança apresenta um grande potencial para a pesquisa, pois possui qualidades essenciais a um bom pesquisador: curiosidade, criatividade, sensibilidade, capacidade de observação e abertura a novas experiências. Toda essa potencialidade infantil pode ser trabalhada em sala de aula desde o início do processo de escolarização. Para isso, faz-se necessário que os professores sejam proativos e colaborativos. O planejamento do trabalho cotidiano e a definição de objetivos claros de aprendizagem são fundamentais. Ressalta-se a importância de se partir do potencial de cada criança e dos próprios docentes.

Concordamos com Lima (2008, p. 19) que o ingresso da criança na escola tem vários objetivos, e, dentre tais objetivos, há um claro e preciso: aprender determinados conhecimentos e dominar instrumentos específicos que lhe possibilitem a aprendizagem. $\mathrm{E}$ aprender, sobretudo, a utilizar essas aquisições não só para o seu desenvolvimento pessoal como para o do coletivo, colocando o conhecimento a serviço do bem comum. A relação da criança com o adulto na escola é mediada pelo conhecimento formal. O professor já se apropriou de uma significativa parcela desse conhecimento produzido historicamente pela humanidade e o educando está em processo de apropriação. É por meio da interação entre eles, mediada pelo conhecimento, que a efetiva aprendizagem acontece.

A proposta de Iniciação à Pesquisa possibilita o compartilhamento do processo de aprendizagem entre as crianças, pois todas no grupo aprendem com a produção de cada uma. Nos momentos vivenciados em sala de aula, observamos que há uma troca de conhecimentos em relação a vários aspectos envolvidos na produção dos registros individuais, seja na seleção da informação, na escrita ou na produção de desenhos ilustrativos. Há um processo de colaboração mútua em relação às produções individuais.

Os grupos de pesquisa proporcionam a instauração de uma atitude investigativa nas crianças e a essa prática mostra-se como fundamental para ensinar a aprender. Isso pressupõe um grande trabalho de orientação das crianças por parte de seus professores. Trata-se de uma proposta que exige um profundo envolvimento dos adultos mediadores, 
que conduzem o processo disponibilizando fontes confiáveis de informação e de conhecimento e orientando todo o efervescente processo de pesquisa que acontece em sala de aula.

Nesse processo de construção coletiva e individual de saberes, é essencial considerar o conhecimento prévio da criança como informação relevante e propulsora de todo o processo investigativo que se instaura em sala de aula, numa lógica que se configura da seguinte forma: partir do que se sabe para o que se quer conhecer. O trabalho realizado demonstrou como a criança, curiosa por natureza, apresenta explicações para o que acontece ao seu redor e tenta compreender os principais fenômenos que observa.

Partir, metodologicamente, da experiência cultural do educando abre caminho para a construção de um currículo que reconhece o saber do sujeito que aprende, mas preocupa-se com a ampliação desse saber, garantindo, assim, que todos tenham direito à informação de qualidade produzida historicamente pela sociedade. Percebemos que considerar a experiência cultural do sujeito favorece o seu processo de aprendizagem.

Habilidades cognitivas de observação, leitura, registro de sínteses, representação por desenhos, dentre outras são trabalhadas cotidianamente quando desenvolvemos os grupos de pesquisa. Além dessas, trabalhamos também com habilidades sociais necessárias ao processo de construção de conhecimento como saber ouvir, aceitar a opinião do outro e colaborar com a aprendizagem dos pares. Essa colaboração é de fundamental importância no processo, em virtude da extensão de trabalho que a proposta do grupo de pesquisa significa para aqueles que o propõe. É uma proposta que demanda tempo, energia e profundo comprometimento profissional dos professores.

É possível afirmar que o trabalho desenvolvido com a turma de primeiro ano mostrou-se como uma proposta de grande potencial para o processo de ensino e de aprendizagem. O trabalho investigativo com crianças pequenas a partir da apresentação de algumas possibilidades didáticas traz ao ensino um caráter interativo que envolve atividades em que os alunos considerem as explicações científicas para além dos discursos dogmáticos. A possibilidade de aprender por meio da pesquisa é instigadora e desafiadora, tanto para as crianças quanto para os professores. Acreditamos que a orientação que os docentes oferecem aos grupos durante a pesquisa é fundamental nesse processo. Outro aspecto essencial é possibilitar que os educandos escolham temas de seu interesse. Trabalhar com Iniciação à Pesquisa abre possibilidades para a ampliação dos conteúdos do currículo, uma vez que proporciona a produção coletiva de novos conhecimentos no cotidiano desse espaço complexo que é a sala de aula.

\section{Referências}

ALBERGARIA, Danilo. Pensando criticamente as novas abordagens de ensino. ComCiência: revista eletrônica de jornalismo científico, Campinas, v. 115, 2010. Disponível em: http://www.comciencia. br/comciencia/. Acesso em: 30 nov. 2015.

BAGNO, Marcos. Pesquisa na escola: o que é, como se faz. São Paulo: Loyola, 2007.

BRASIL. Secretaria de Educação Fundamental. Parâmetros curriculares nacionais: ciências naturais. Brasília, DF: MEC; SEF, 1997. 136 p.

BRASIL. Ministério da Educação. Secretaria de Educação Básica. Secretaria de Educação Continuada, Alfabetização, Diversidade e Inclusão. Conselho Nacional da Educação. Diretoria de Currículos e Educação Integral. Diretrizes Curriculares Nacionais da Educação Básica. Brasília, DF: MEC: SEB: DICEI, 2013.

BRASIL. Base Nacional Curricular Comum: ciências. Brasília, DF: MEC, 2017. Disponível em: http://basenacionalcomum.mec.gov.br/a-base. Acesso em 25 out. 2018.

FREIRE, Paulo. Pedagogia do Oprimido. Rio de Janeiro: Paz e Terra, 1974.

LIMA, Elvira Souza. Desenvolvimento e aprendizagem na escola. São Paulo: GEDH, 2002. 
LIMA, Elvira Souza. Atividades de estudo. São Paulo: GEHD, 2009.

LIMA, Elvira Souza. Indagações sobre currículo: currículo e desenvolvimento humano. Brasília, DF: Ministério da Educação, Secretaria de Educação Básica, 2007.

LORENZETTI, Leonir; DELIZOICOV, Demétrio. Alfabetização científica no contexto das séries iniciais. Ensaio: Pesquisa em Educação em Ciências, Belo Horizonte, v. 3, n. 1, jan./jun. 2001.

OLIVEIRA, Jane Raquel Silva de. Contribuições e abordagens das atividades experimentais no ensino de ciências: reunindo elementos para a prática docente. Acta Scientiae, Canoas, v. 12, n. 1, p. 139-153, jan./jun. 2010.

PERRENOUD, P. Não mexam na minha avaliação! Para uma abordagem sistêmica da mudança pedagógica. In: ESTRELA, Albano; NÓVOA, António, (org.). Avaliações em Educação: novas perspectivas. Porto: Porto Editora, 1999.

VIGOTSKI, Lev Semyonovich. A formação social da mente. São Paulo: Martins Fontes, 2002. 